BARnes, E. M. (1956). J. gen. Microbiol. 14, 57-68

\title{
Tetrazolium Reduction as a Means of Differentiating Streptococcus faecalis from Streptococcus faecium
}

\author{
By ELLA M. BARNES \\ Low Temperature Station for Research in Biochemistry and Biophysics, University \\ of Cambridge and Department of Scientific and Industrial Research
}

SUMMARY: Tetrazolium (2:3:5-triphenyltetrazolium chloride) was used in a glucose nutrient medium to show the considerable differences in reducing properties between some of the Lancefield group $D$ streptococci. The ability to reduce tetrazolium to formazan, in a glucose-containing medium, at an initial $\mathrm{pH} 6 \cdot 0$, distinguishes strains of Streptococcus faecalis from those of $S$. faecium (Orla-Jensen) which for many years have been classified in the same species as $\boldsymbol{S}$. faecalis. Differences in reducing properties correspond with many other tests now used to separate these species. Measurements of the oxidation-reduction potentials in growing cultures showed that $S$. faecalis produced an $E_{h}$ value about $150 \mathrm{mV}$. lower than $S$. faecium. Confirmation of the differences in reducing properties of these species was obtained by testing 68 freshly isolated strains of $S$. faecium and 34 strains of $S$. faecalis.

The problem of differentiating the streptococci within the Lancefield group D has received considerable attention in the past few years because many of these organisms are important clinically and also because their unusual tolerance of salt, temperature and acid conditions renders them important in food spoilage. Considerable advances have been made in defining the species concerned, by correlating physiological reactions with serological types (Skadhauge, 1950; Seelemann \& Carstens, 1951; Sharpe \& Shattock, 1952). A case has been made for the re-introduction of the species Streptococcus faecium (Orla-Jensen, 1919) as a species separate from $S$. faecalis and its haemolytic and proteolytic variants zymogenes and liquefaciens (Shattock, 1955).

Streptococcus faecalis and $S$. faecium share the characteristics usually described as the 'Sherman criteria' for the enterococcus group (Sherman, 1937), but they may be distinguished by certain other properties (see Table 1). The necessity for distinguishing between these two species may be briefly explained as follows. (1) Both organisms have been isolated in human infections, but Skadhauge (1950) suggests that there may be a difference in the sites of infections with the two organisms. (2) Faecal streptococci have been implicated in a number of outbreaks of food-poisoning (Dack, 1944), and it is not yet known whether one or more types are responsible. (3) Although both species have been isolated in food spoilage, e.g. from canned hams, there is a suggestion that one ( $S$. faecalis) may be indicative of poor hygiene, as this organism is mainly found in human faeces, whilst the other organism may get into the meat from the gut of the animal concerned, in this case, the pig (Ingram \& Barnes, 1955; Barnes \& Ingram, 1955). (4) S.faecalis is used as an indicator organism for water pollution. 
Skadhauge (1950) and Barnes \& Ingram (1955) found that there was a difference in the reducing properties of these two species as shown in litmus milk: Streptococcus faecalis usually produces reduction, acid, and clotting in $24 \mathrm{hr}$., but $S$. faecium shows less reduction and sometimes only acid production. The other two species in the Lancefield group $\mathrm{D}, S$. durans and $S$. bovis, do not possess strong powers of reducing litmus milk, and usually cause only acidity or acidity and clotting.

Table 1. The differentiation of Streptococcus faecalis from S. faecium

$S$. faecalis and $S$. faecium share the following characteristics (Sherman criteria):

Lancefield group D.

Growth in the presence of $40 \%$ bile.

Fermentation of glucose, lactose and maltose.

Growth at $10^{\circ}$ and $4.5^{\circ}$.

Growth at pH $9 \cdot 6$ and in the presence of $6.5 \% \mathrm{NaCl}$.

Survival at $60^{\circ}$ for $30 \mathrm{~min}$.

Growth in Sherman's methylene blue milk (0.1\%).

S. faecalis, S. faecalis var.

They differ as follows:

zymogenes and $\mathbf{S}$. faecalis var. liquefaciens

A number of serological types.

Growth in the presence of $1 / 2500$ potassium tellurite.

Strong fermentation reactions; mannitol and sorbitol always fermented, arabinose seldom.

Strong reduction in litmus milk prior

to acid and clot.

Active production of tyrosine decarboxylase.

\section{S. faecium}

Several serological types but distinct from the $S$. faecalis types.

Inhibited by $1 / 2500$ potassium tellurite.

More variable fermentation reactions, particularly with mannitol; arabinose always fermented, sorbitol seldom.

Less reduction of litmus milk and sometimes no reduction, only acidity.

Some strains are active producers of tyrosine decarboxylase, whilst others do not produce it.

2:3:5-Triphenyltetrazolium chloride ('tetrazolium' subsequently) has often been used recently as a redox indicator. It is colourless in the oxidized form and is reduced to the insoluble red triphenylformazan in the presence of suitable reducing substances or systems. The $E_{0}^{\prime}$ was shown by Jerchel \& Mohle (1944) to be $-0.08 \mathrm{~V}$. at pH 6.72. Laxminarayana \& Iya (1953) found that certain unnamed strains of faecal streptococci varied in their ability to reduce tetrazolium. It was decided to adapt some of their methods to study tetrazolium reduction by known species of Lancefield group D streptococci, in particular Streptococcus faecalis and S. faecium.

\section{METHODS}

\section{Estimation of tetrazolium reduction by faecal streptococci}

Culture medium (subsequently called TG medium). The composition of the medium was $(\%, w / v)$ : peptone (Evans's), 1; Lab Lemco, 1; NaCl, 0.5; glucose, 1; distilled water; 2:3:5-triphenyltetrazolium chloride to give $375 \mu \mathrm{g} / 5 \mathrm{ml}$. medium. In the experiments described below the initial $\mathrm{pH}$ value was varied between $6 \cdot 0$ and $7 \cdot 6$. 
The medium containing the peptone, Lemco and salt was adjusted to the required $\mathrm{pH}$ value and autoclaved at $15 \mathrm{lb}$. $/ \mathrm{sq}$.in. for $20 \mathrm{~min}$. in $95 \mathrm{ml}$. lots. After autoclaving, $5 \mathrm{ml}$. of a $20 \%(\mathrm{w} / \mathrm{v})$ glucose solution (sterilized by autoclaving at $10 \mathrm{lb}$./sq.in. for $10 \mathrm{~min}$.) were added together, with $0.75 \mathrm{ml}$. of a $1 \%$ solution of the tetrazolium salt. (The tetrazolium solution was sterilized by steaming for $30 \mathrm{~min}$.). The TG medium was then aseptically pipetted in $5 \mathrm{ml}$. lots into $1 \mathrm{oz}$. screw-capped bottles.

Cultural conditions. The TG medium ( $5 \mathrm{ml}$.) was inoculated with $0.025 \mathrm{ml}$. of an $18 \mathrm{hr}$. broth culture to give $c .1 \times 10^{7}$ organisms $/ \mathrm{ml}$. The inoculated bottles were incubated for $24 \mathrm{hr}$. at $37^{\circ}$ and the reduced tetrazolium (insoluble red formazan) was extracted as follows.

Extraction of formazan from cultures. A culture $(5 \mathrm{ml}$.) was shaken successively with 5, 2 and $2 \mathrm{ml}$. of $n$-butanol to extract all the formazan. The butanol extracts were withdrawn with a Pasteur pipette into marked centrifuge tubes and the volume made to $10 \mathrm{ml}$. with butanol. The solution was mixed and centrifuged to obtain a clear extract. The colour intensity of the extract was measured in an EEL. (Evans Electroselenium Ltd.) colorimeter with filter no. 625 . The percentage reduction of tetrazolium was calculated by reference to a standard curve (see below) on the assumption that it was directly proportional to the amount of formazan produced.

Errors of the method. Care must be taken that the tetrazolium solution is freshly prepared and stored in the dark. In media where considerable reduction has taken place (e.g. with Streptococcus faecalis) sufficient formazan to give a visible colour adheres to the organisms during growth and cannot be removed by the butanol extraction. However, even in these cases virtually all the formazan may be recovered (see Fig. 2), the quantity adsorbed evidently being insufficient to interfere with the estimation.

Standard curve for estimation of tetrazolium reduction. Bottles of TG medium $(5 \mathrm{ml}$., pH $7 \cdot 0$ ) containing $375,300,225,150$ or $75 \mu \mathrm{g}$. tetrazolium salt/bottle were treated with $1 \mathrm{ml} . \mathrm{N}-\mathrm{NaOH}$ and several mg. ascorbic acid to reduce all the tetrazolium present (Fairbridge, Willis \& Booth, 1951). The bottles were left for $30 \mathrm{~min}$. and then adjusted to about $\mathrm{pH} 4.5$ with $\mathrm{N}-\mathrm{HCl}$ (to give a $\mathrm{pH}$ for extraction comparable to that obtained after the growth of the streptococci). The formazan was extracted from the broths with $n$-butanol (as above) and a calibration curve (Fig. 1) obtained by relating the colorimeter reading to the initial concentration of tetrazolium salt (when completely reduced to formazan).

Measurement of growth. The total number of organisms present was estimated either by a direct microscopical count or by a turbidimetric method using the EEL. nephelometer, a standard curve having been made by relating direct microscopical count to nephelometer reading.

$E_{h}$ measurements. The redox potentials in the broth cultures were measured by the method described by Hewitt (1950). In this case tall beakers containing $\mathbf{2 5} \mathrm{ml}$. medium were fitted with bungs carrying the sampling tube, the platinum electrode and a saturated $\mathrm{KCl}$ agar bridge connected to the calomel half-cell. The platinum electrodes were sterilized separately by leaving in 
$70 \%(\mathrm{v} / \mathrm{v})$ ethanol overnight and then rinsing with sterile water and drying with sterile cotton-wool. In these experiments the object was not to eliminate all the air but to imitate as far as possible the conditions existing in TG medium in the $1 \mathrm{oz}$. bottles used for routine tests. The inoculum for these experiments was $1 \%(\mathrm{v} / \mathrm{v})$ of an overnight broth culture so that the major part of the experiment was concluded in 8-10 hr., although readings were also made after $24 \mathrm{hr}$. When tetrazolium estimations were made on duplicate control solutions in $1 \mathrm{oz}$. bottles the inoculum was also increased to $1 \%(\mathrm{v} / \mathrm{v})$ but the cultures were incubated for $\mathbf{2 4} \mathrm{hr}$. in the usual manner.

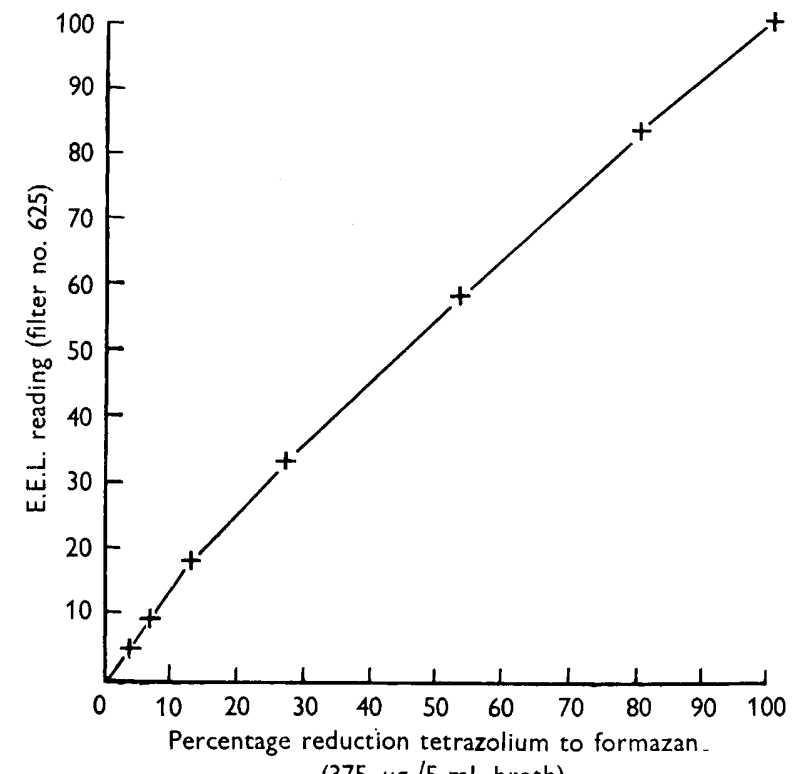

(375 $\mu \mathrm{g} . / 5 \mathrm{ml}$. broth)

Fig. 1. Calibration curve relating the percentage reduction of $375 \mu \mathrm{g}$. of tetrazolium (as formazan) to the reading on the EEL. colorimeter.

\section{RESULTS}

For a preliminary survey of the ability of group D streptococci to reduce tetrazolium to formazan, named strains were obtained from Dr P. M. Frances Shattock (University of Reading) and Dr M. Elisabeth Sharpe (National Institute for Research in Dairying). The tests were carried out by the method described above; the $\mathrm{pH}$ value of the TG medium was $\mathbf{7 \cdot 2 - 7 \cdot 4}$. At the same time a comparison was made with the reaction in litmus milk. The results are given in Table 2. The three strains of Streptococcus faecalis showed over $80 \%$ reduction of tetrazolium to the insoluble red formazan and produced rapid reduction, acid and clot in litmus milk. The five strains of $S$. faecium produced less than $45 \%$ reduction of tetrazolium, and litmus milk was only partially reduced in 24 hr. $S$. bovis and $S$. durans reduced the tetrazolium by less than $10 \%$, and produced little change in litmus milk in $24 \mathrm{hr}$. 
These results encouraged further experiments with tetrazolium and freshly isolated strains of Streptococcus faecium and $S$. faecalis. The identifications were based on the properties shown in Table 1. Over a period of several months 68 strains of $S$. faecium and 34 strains of $S$. faecalis were tested in TG medium ( $\mathrm{pH} 6 \cdot 8-7 \cdot 0$ ) and the differences in their reducing powers was found to be quite characteristic. These results are shown in Fig. 2. Only 6 strains of $S$. faecium gave over $50 \%$ reduction of tetrazolium, whilst 2 strains of $S$. faecalis gave less than $50 \%$ reduction.

Table 2. A comparison of the reaction in litmus milk with the reduction of tetrazolium for several species of Lancefield group $D$ streptococci

\begin{tabular}{|c|c|c|c|c|c|}
\hline \multirow[b]{3}{*}{ Species } & & & & \multicolumn{2}{|c|}{ TG medium } \\
\hline & \multicolumn{3}{|c|}{ Litmus milk } & \multirow{2}{*}{$\begin{array}{l}\text { Total count } \\
\times 10^{9} / \mathrm{ml} \text {. } \\
\text { after } 24 \mathrm{hr} \text {. }\end{array}$} & \multirow{2}{*}{$\begin{array}{c}\% \\
\text { reduction to } \\
\text { formazan }\end{array}$} \\
\hline & $6 \mathrm{hr}$. & $24 \mathrm{hr}$. & 3 days & & \\
\hline S. faecalis (N. 83) & $\mathbf{R *}$ & Rc & RAC & $2 \cdot 0$ & 86 \\
\hline $\begin{array}{l}\text { S. faecalis var. liquefaciens } \\
\text { (GB. 122) }\end{array}$ & $\mathbf{r}$ & RCAlq. & RCAlq. & $\mathbf{2} \cdot \mathbf{0}$ & 91 \\
\hline $\begin{array}{l}\text { S. faecalis var. zymogenes } \\
\text { (N. 37) }\end{array}$ & $\mathbf{R}$ & RAC & RAC & $\mathbf{2} \cdot \mathbf{0}$ & 85 \\
\hline S. faecium $2766 / 2$ & ne & A & ARC & $4 \cdot 0$ & 24 \\
\hline S. faecium 2767 & ne & Ar & ARC & $2 \cdot 5$ & 31 \\
\hline S. faecium 2678 & ne & Ar & ARC & $3 \cdot 0$ & 35 \\
\hline S. faecium S. 748 & $\mathrm{r}$ & Ar & ARC & $3 \cdot 0$ & 39 \\
\hline S. faecium $2766 / 1$ & ne & $\mathrm{Ar}$ & ARC & $3 \cdot 0$ & 43 \\
\hline S. durans & ne & $\mathbf{A}$ & AR & $2 \cdot 5$ & 10 \\
\hline S. bovis & nc & nc & $\mathbf{A}$ & 2.5 & 9 \\
\hline
\end{tabular}

* nc, no change; A, acid; r, some reduction; R, strong reduction; c, slight clot; C, clot, lq., liquefaction.

Relationship of redox potential to tetrazolium reduction

In order to determine whether differences in tetrazolium reduction were related to different reducing powers of these organisms, measurements were made of the actual oxidation-reduction potentials of cultures in TG medium. Tests which were carred out separately in tetrazolium glucose medium of different initial pH values showed that after the first few hours the growth rates and $\mathrm{pH}$ changes were comparable for strains of Streptococcus faecalis, $S$. faecium, $S$. durans and $S$. bovis, as shown in Table 3 . Thus any recorded ultimate differences in redox potential would be a reflexion of different reducing properties of the organisms concerned, rather than a function of the $\mathrm{pH}$ value of the culture or of the numbers of organisms present.

In the redox potential experiments described below only the $\mathrm{pH}$ changes are recorded as an index of the growth of the organisms, as it was difficult to obtain homogenous samples for total count without disturbing the redox potential of the medium. Samples were, however, removed at the end of the experiment and these, together with a few samples taken at intervals, showed that the counts were not significantly different from those recorded in Table 3. 


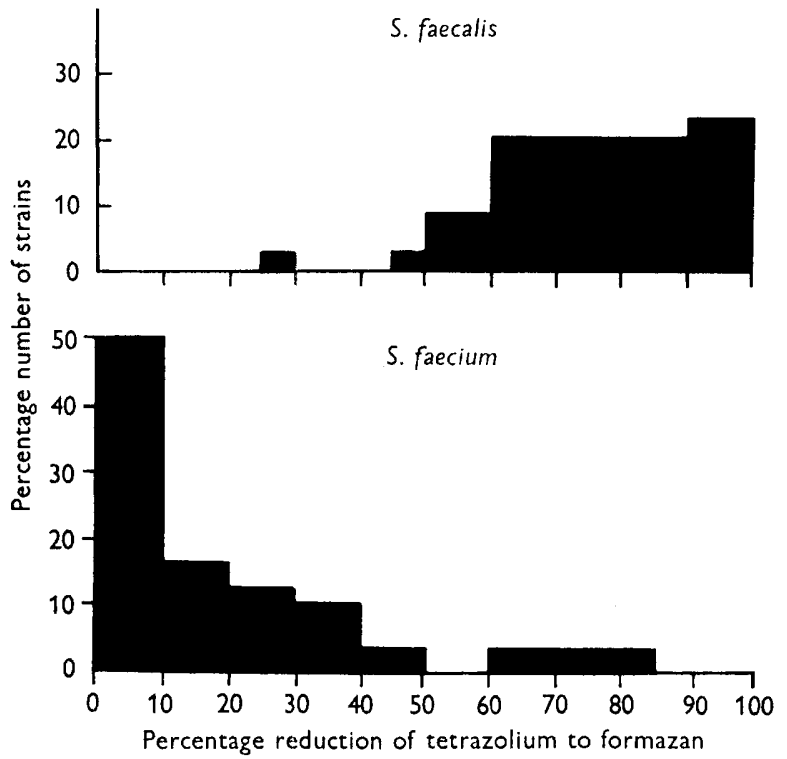

Fig. 2. A comparison of the percentage reduction of tetrazolium to formazan by strains of Streptococcus faecalis and $S$. faecium.

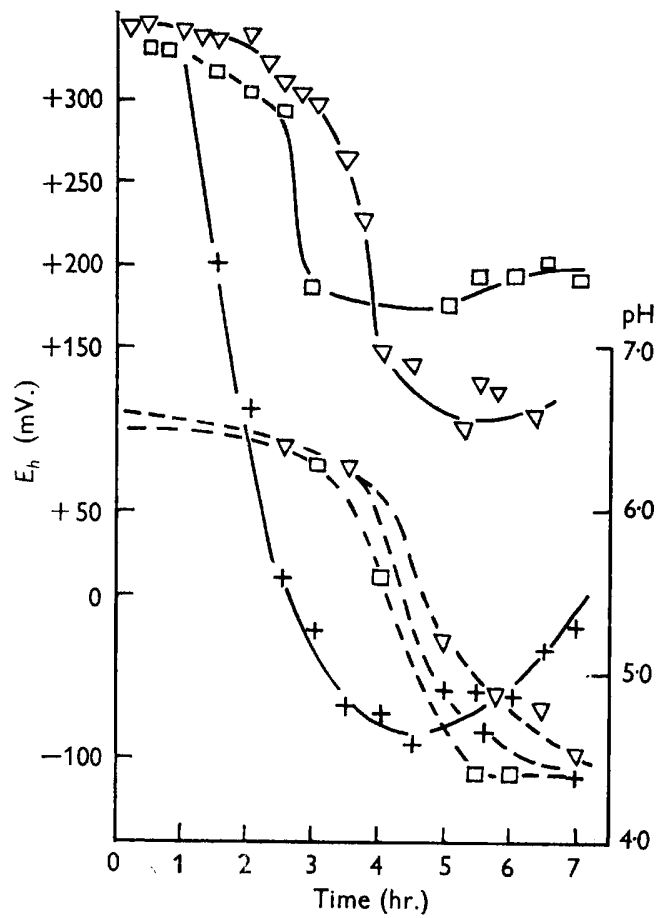

Fig. 3. Changes in the redox potential and pH during the growth of Streptococcus faecalis, $S$. faecium and $S$. bovis.

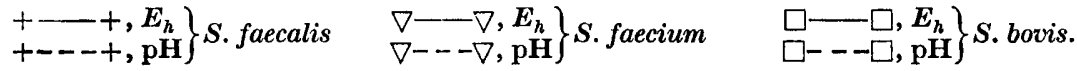


The changes in $E_{h}$ and $\mathrm{pH}$ were followed for $7-8 \mathrm{hr}$. at $37^{\circ}$ when beakers of

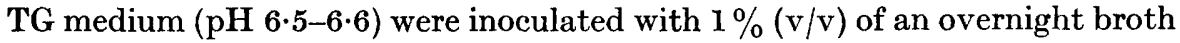
culture of Streptococcus faecalis (N. 83), S. faecium (S. 748) and $S$. bovis (S. 194). The results are shown in Fig. 3. The lowest potential reached in the $S$. faecalis culture was about $E_{h}-90 \mathrm{mV}$., that of $S$. faecium was $+90 \mathrm{mV}$.

Table 3. The effect of initial $\mathrm{pH}$ on the growth and total population in glucose broth of Streptococcus faecalis, S. faecium, S. bovis and S. durans

\begin{tabular}{|c|c|c|c|c|c|c|c|c|c|}
\hline & & & & & Initial & $\mathrm{l} \mathbf{p H}$ & & & \\
\hline & & & $6 \cdot 1$ & & $6 \cdot 6$ & & $7 \cdot 1$ & & $7 \cdot 4$ \\
\hline & $\begin{array}{l}\text { Time } \\
\text { (hr.) }\end{array}$ & $\mathrm{pH}$ & $\begin{array}{c}\text { Total } \\
\text { count } \\
\times 10^{9} / \mathrm{ml}\end{array}$ & $\mathrm{pH}$ & $\begin{array}{c}\text { Total } \\
\text { count } \\
\times 10^{9} / \mathrm{ml}\end{array}$ & pH & $\begin{array}{c}\text { Total } \\
\text { count } \\
\times 10^{\circ} / \mathrm{ml}\end{array}$ & $\mathrm{pH}$ & $\begin{array}{c}\text { Total } \\
\text { count } \\
\times 10^{9} / \mathrm{ml}\end{array}$ \\
\hline S. faecalis & $\begin{array}{r}4 \\
6 \\
24\end{array}$ & $\begin{array}{l}5 \cdot 6 \\
4 \cdot 5 \\
4 \cdot 1\end{array}$ & $\begin{array}{l}0 \cdot 5 \\
2 \cdot 5 \\
4 \cdot 0\end{array}$ & $\begin{array}{l}6 \cdot 5 \\
4 \cdot 5 \\
4 \cdot 1\end{array}$ & $\begin{array}{l}0 \cdot 7 \\
4 \cdot 0 \\
5 \cdot 5\end{array}$ & $\begin{array}{l}6 \cdot 9 \\
4 \cdot 5 \\
4 \cdot 1\end{array}$ & $\begin{array}{l}0 \cdot 7 \\
5 \cdot 5 \\
6 \cdot 5\end{array}$ & $\begin{array}{l}7 \cdot 0 \\
4 \cdot 5 \\
4 \cdot 1\end{array}$ & $\begin{array}{l}1 \\
5 \cdot 5 \\
6\end{array}$ \\
\hline $\begin{array}{l}\text { S. faecalis var. } \\
\text { liquefaciens }\end{array}$ & $\begin{array}{r}4 \\
6 \\
24\end{array}$ & $\begin{array}{l}5 \cdot 8 \\
4 \cdot 5 \\
4 \cdot 1\end{array}$ & $\begin{array}{l}0 \cdot 5 \\
2 \cdot 0 \\
3 \cdot 0\end{array}$ & $\begin{array}{l}6 \cdot 4 \\
4 \cdot 5 \\
4 \cdot 1\end{array}$ & $\begin{array}{l}0.9 \\
3 \cdot 5 \\
4 \cdot 5\end{array}$ & $\begin{array}{l}6 \cdot 8 \\
4 \cdot 5 \\
4 \cdot 1\end{array}$ & $\begin{array}{l}1 \cdot 0 \\
4 \cdot 5 \\
5 \cdot 0\end{array}$ & $\begin{array}{l}6 \cdot 9 \\
4 \cdot 5 \\
4 \cdot 1\end{array}$ & $\begin{array}{l}0 \cdot 9 \\
4 \cdot 5 \\
5 \cdot 0\end{array}$ \\
\hline $\begin{array}{l}\text { S. faecalis var. } \\
\text { zymogenes }\end{array}$ & $\begin{array}{r}4 \\
6 \\
24\end{array}$ & $\begin{array}{l}5 \cdot 8 \\
4 \cdot 5 \\
4 \cdot 1\end{array}$ & $\begin{array}{l}0 \cdot 5 \\
2 \cdot 5 \\
4 \cdot 0\end{array}$ & $\begin{array}{l}6 \cdot 4 \\
4 \cdot 5 \\
4 \cdot 1\end{array}$ & $\begin{array}{l}0 \cdot 7 \\
4 \cdot 0 \\
5 \cdot 0\end{array}$ & $\begin{array}{l}6 \cdot 4 \\
4 \cdot 5 \\
4 \cdot 1\end{array}$ & $\begin{array}{l}1 \cdot 0 \\
5 \cdot 0 \\
6 \cdot 0\end{array}$ & $\begin{array}{l}6 \cdot 9 \\
4 \cdot 5 \\
4 \cdot 1\end{array}$ & $\begin{array}{l}0 \cdot 9 \\
5 \\
6\end{array}$ \\
\hline S. faecium $2766 / 1$ & $\begin{array}{r}4 \\
6 \\
24\end{array}$ & $\begin{array}{l}6 \cdot 0 \\
4 \cdot 5 \\
4 \cdot 1\end{array}$ & $\begin{array}{l}0 \cdot 4 \\
3 \cdot 5 \\
4 \cdot 0\end{array}$ & $\begin{array}{l}6 \cdot 5 \\
4 \cdot 5 \\
4 \cdot 1\end{array}$ & $\begin{array}{l}0 \cdot 4 \\
5 \cdot 0 \\
5 \cdot 5\end{array}$ & $\begin{array}{l}6 \cdot 9 \\
4 \cdot 5 \\
4 \cdot 1\end{array}$ & $\begin{array}{l}0 \cdot 5 \\
5 \cdot 5 \\
6 \cdot 5\end{array}$ & $\begin{array}{l}7 \cdot 1 \\
4 \cdot 5 \\
4 \cdot 1\end{array}$ & $\begin{array}{l}0 \cdot 4 \\
5 \cdot 5 \\
6\end{array}$ \\
\hline S. faecium S. 748 & $\begin{array}{r}4 \\
6 \\
24\end{array}$ & $\begin{array}{l}5 \cdot 9 \\
4 \cdot 5 \\
4 \cdot 1\end{array}$ & $\begin{array}{l}0 \cdot 4 \\
3 \cdot 0 \\
4 \cdot 0\end{array}$ & $\begin{array}{l}6 \cdot 5 \\
4 \cdot 5 \\
4 \cdot 1\end{array}$ & $\begin{array}{l}0 \cdot 5 \\
4 \cdot 5 \\
5 \cdot 5\end{array}$ & $\begin{array}{l}6 \cdot 9 \\
4 \cdot 5 \\
4 \cdot 1\end{array}$ & $\begin{array}{l}0.5 \\
5 \cdot 5 \\
6 \cdot 0\end{array}$ & $\begin{array}{l}7 \cdot 1 \\
4 \cdot 5 \\
4 \cdot 1\end{array}$ & $\begin{array}{l}0 \cdot 5 \\
5 \cdot 5 \\
6 \cdot 0\end{array}$ \\
\hline S. faecium 2678 & $\begin{array}{r}4 \\
6 \\
24\end{array}$ & $\begin{array}{l}6 \cdot 0 \\
4 \cdot 5 \\
4 \cdot 1\end{array}$ & $\begin{array}{l}0 \cdot 4 \\
3 \cdot 5 \\
4 \cdot 5\end{array}$ & $\begin{array}{l}6 \cdot 4 \\
4 \cdot 5 \\
4 \cdot 1\end{array}$ & $\begin{array}{l}0 \cdot 5 \\
5 \cdot 0 \\
5 \cdot 5\end{array}$ & $\begin{array}{l}6 \cdot 9 \\
4 \cdot 5 \\
4 \cdot 1\end{array}$ & $\begin{array}{l}0 \cdot 6 \\
5 \cdot 5 \\
6 \cdot 0\end{array}$ & $\begin{array}{l}7 \cdot 0 \\
4 \cdot 5 \\
4 \cdot 1\end{array}$ & $\begin{array}{l}0 \cdot 6 \\
5 \cdot 9 \\
6 \cdot 0\end{array}$ \\
\hline S. durans & $\begin{array}{r}4 \\
6 \\
24\end{array}$ & $\begin{array}{l}5 \cdot 9 \\
4 \cdot 5 \\
4 \cdot 1\end{array}$ & $\begin{array}{l}0 \cdot 4 \\
3 \cdot 0 \\
4 \cdot 0\end{array}$ & $\begin{array}{l}6 \cdot 4 \\
4 \cdot 5 \\
4 \cdot 1\end{array}$ & $\begin{array}{l}0 \cdot 6 \\
4 \cdot 4 \\
5 \cdot 0\end{array}$ & $\begin{array}{l}6 \cdot 9 \\
4 \cdot 5 \\
4 \cdot 1\end{array}$ & $\begin{array}{l}0 \cdot 6 \\
5 \cdot 0 \\
6 \cdot 0\end{array}$ & $\begin{array}{l}7 \cdot 0 \\
4 \cdot 5 \\
4 \cdot 1\end{array}$ & $\begin{array}{l}0 \cdot 6 \\
5 \cdot 5 \\
6\end{array}$ \\
\hline S. bovis & $\begin{array}{r}4 \\
6 \\
24\end{array}$ & $\begin{array}{l}6 \cdot 1 \\
4 \cdot 5 \\
4 \cdot 1\end{array}$ & $\begin{array}{l}0 \cdot 3 \\
1 \cdot 5 \\
3 \cdot 5\end{array}$ & $\begin{array}{l}6 \cdot 5 \\
4 \cdot 5 \\
4 \cdot 1\end{array}$ & $\begin{array}{l}0 \cdot 4 \\
3 \cdot 0 \\
5 \cdot 5\end{array}$ & $\begin{array}{l}7 \cdot 0 \\
5 \cdot 7 \\
4 \cdot 1\end{array}$ & $\begin{array}{l}0 \cdot 4 \\
2 \cdot 5 \\
6 \cdot 0\end{array}$ & $\begin{array}{l}7 \cdot 3 \\
5 \cdot 8 \\
4 \cdot 1\end{array}$ & $\begin{array}{l}0 \cdot 4 \\
2 \cdot 5 \\
5 \cdot 0\end{array}$ \\
\hline
\end{tabular}

and $S$. bovis $+180 \mathrm{mV}$. Thus the reducing conditions were much greater in the $S$. faecalis culture than in either the $\boldsymbol{S}$. faecium or $\boldsymbol{S}$. bovis cultures. This experiment was repeated on several occasions, and the marked difference between $S$. faecalis and $S$. faecium always obtained. Although the $S$. faecium strain used was usually more reducing than $S$. bovis, occasionally it showed little difference from $S$. bovis in the TG medium. As this investigation was concerned mainly with the differences between $S$. faecium and $S$. faecalis detailed investigations of the relationship of $S$. faecium to $S$. bovis were not made. 


\section{Effect of changes in the medium on tetrazolium reduction}

Alteration in the initial $p H$ value of the glucose tetrazolium medium. The initial value of samples of TG medium was adjusted to $6 \cdot 1,6 \cdot 6,7 \cdot 1$ and $7 \cdot 4$ respectively, and inoculated with a number of strains of Streptococcus faecalis, $S$. durans and $S$. bovis. The results obtained from a number of experiments are shown in Fig. 4 where tetrazolium reduction is related to the initial $\mathrm{pH}$ value of the

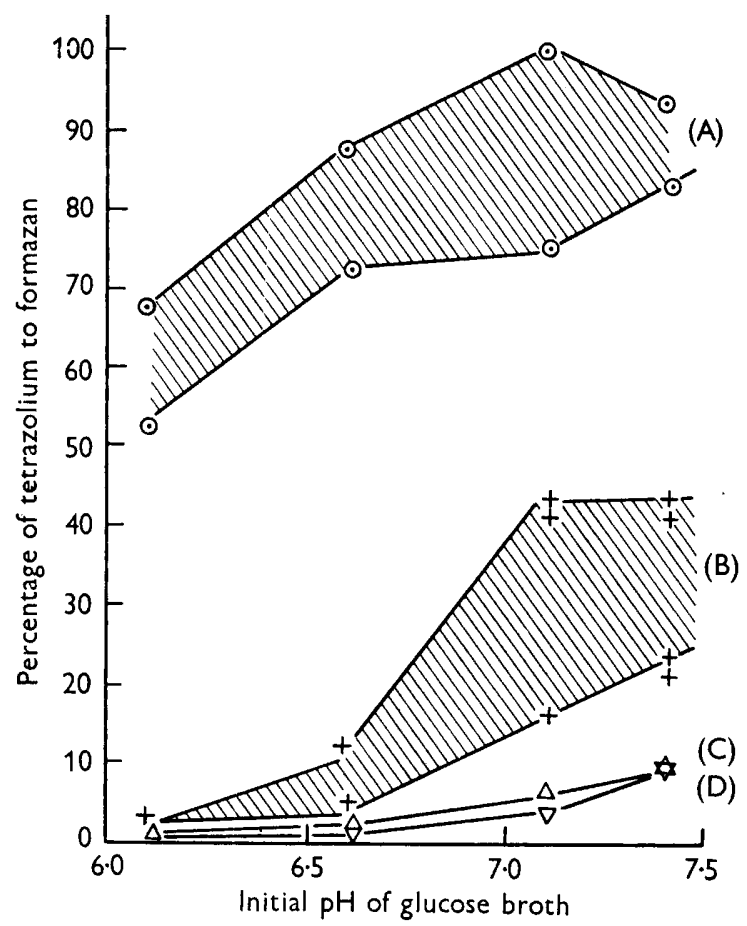

Fig. 4. The effect of the initial pH of glucose broth on the reduction of tetrazolium to formazan by (A) S. faecalis, (B) S. faecium, (C) S. durans and (D) S. bovis.

medium. With the strains of $S$. faecalis there was over $50 \%$ reduction of tetrazolium to formazan at all $\mathrm{pH}$ values, whilst with $\boldsymbol{S}$. durans and $\boldsymbol{S}$. bovis there was less than $10 \%$. In the case of $S$. faecium the initial $\mathrm{pH}$ value considerably influenced the amount of formazan produced during growth. It can be seen that in order to get the maximum differentiation between S. faecium and $S$. faecalis the test should be carried out at $\mathrm{pH} \mathbf{6} \cdot \mathbf{0}-\mathbf{6} \cdot \mathbf{2}$. With a strain of $S$. faecium an attempt was made to correlate the amount of formazan produced in the media of different initial $\mathrm{pH}$ values with the lowest redox potential obtained in that particular medium. Although there was no absolute correlation the lowest potentials recorded varied from $E_{h}+210 \mathrm{mV}$. in medium of initial $\mathrm{pH} 6 \cdot 0$ to $E_{h}+120 \mathrm{mV}$. when the initial $\mathrm{pH}$ was $7 \cdot 6$. In the same experiment the reduction of tetrazolium varied from less than 2.0 to $28 \%$. 
Effect of alterations in the composition of the medium. The effect on tetrazolium reduction of growing the organisms in media where there was only a slight change in $\mathrm{pH}$ value was tested in the following manner. Samples of Hartley's tryptic digest broth containing the usual concentration of tetrazolium were adjusted to $\mathrm{pH} 6 \cdot 0,6 \cdot 4,6 \cdot 8$ and $7 \cdot 2$. The broths were inoculated with strains of Streptococcus faecalis, $S$. faecium and $S$. bovis, and incubated for $24 \mathrm{hr}$. In every case there was more than $\mathbf{5 0} \%$ reduction of tetrazolium to formazan, i.e. no difference was detected in the reducing properties of the organisms. In order to explain this a redox potential experiment was set up where TG medium and digest broth at $\mathrm{pH} 6 \cdot 1-6 \cdot 2$ were compared under

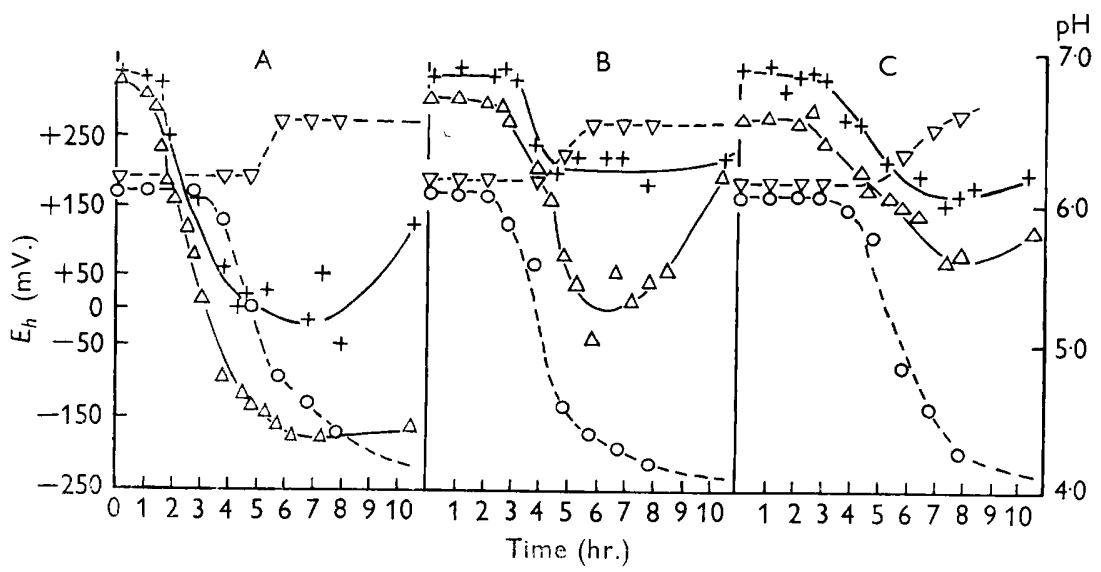

Fig. 5. Changes in $E_{h}$ and pH of (A) S. faecalis, (B) S. faecium and (C) S. bovis when grown in glucose broth and digest broth.

$$
\left.\left.\begin{array}{cc}
+-+, \boldsymbol{E}_{h} \\
\bigcirc---O, \mathrm{pH}
\end{array}\right\} \text { in glucose broth } \begin{array}{l}
\triangle-\triangle, \boldsymbol{E}_{h} \\
\nabla---\nabla, \mathrm{pH}
\end{array}\right\} \text { in digest broth. }
$$

identical conditions, with inocula of the three different species. Changes in redox potential and $\mathrm{pH}$ are shown in Fig. 5. In the digest media the $\mathrm{pH}$ value rose and the actual oxidation-reduction potentials were much lower, by 80 or more $\mathrm{mV}$., than those reached in the glucose media. Even in the case of $S$. bovis the $E_{h}$ of the digest broth was as low as $+74 \mathrm{mV}$. so that all three species then reduced the tetrazolium.

Reduction of tetrazolium at $\mathrm{pH} 6 \cdot \mathbf{0}$. From the above experiments it was apparent that the best medium to use for obtaining the maximum differentiation between Streptococcus faecalis and $S$. faecium was a TG medium of initial $\mathrm{pH} 6 \cdot \mathbf{0}-6 \cdot 2$, as the redox potentials reached in this medium were such that there was no reduction with cultures of $S$. faecium but over $50 \%$ reduction with $S$. faecalis. In view of a statement by Jámbor (1954) that at $\mathrm{pH}$ values below $6 \cdot 0$ tetrazolium is partially reduced to a colourless compound, it was decided to estimate the residual unreduced tetrazolium in the cultures to see whether all the initial tetrazolium could be accounted for.

Samples of TG medium were inoculated in quadruplicate with Streptococcus faecalis, $S$. faecium or $S$. bovis, and incubated for $24 \mathrm{hr}$. Two bottles were taken 
for the estimation of formazan in the usual manner. The other two bottles were treated with $1 \mathrm{ml}$. of $\mathrm{N}-\mathrm{NaOH}$ followed by a few mg. ascorbic acid to reduce all the residual tetrazolium to formazan. The broths were then acidified by the addition of $1 \mathrm{ml}$. of $\mathrm{N}-\mathrm{HCl}$ and the total formazan extracted from the solution as before. The results are shown in Table 4 . With $S$. faecium and $S$. bovis almost all of the tetrazolium was recovered from the medium so that it had not been reduced by the organisms. In the case of $S$. faecalis about $\mathbf{3 0} \%$ of the tetrazolium was not recovered; the reduction of tetrazolium had

Table 4. The reduction of tetrazolium by Streptococcus faecalis, S. faecium and $\mathrm{S}$. bovis in media of initial $\mathrm{pH} 6 \cdot 0$

Control solution

S. faecalis (N. 83)

S. faecalis var. zymogenes

S. faecium (S. 748)

S. bovis

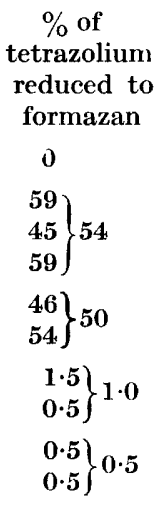

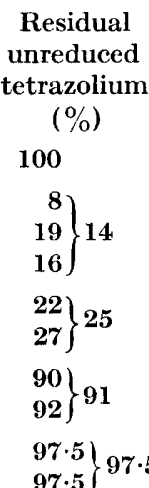

$97 \cdot 5\} 97 \cdot 5$

\section{$\%$ of \\ tetrazolium unaccounted for in the medium}

o

32

25

8

2

either resulted in a mixture of the formazan and a colourless compound, or the formazan had been reduced further. It would therefore be unwise to attempt quantitative estimations of tetrazolium reduction in culture media with an initial $\mathrm{pH}$ of $6 \cdot 0$; but qualitatively, sufficient formazan is produced by strains of $S$. faecalis to give a bright red colour when extracted with butanol as opposed to an almost colourless solution with strains of $S$. faecium.

Qualitative methods for the separation of Streptococcus faecalis and S. faecium

As a result of the above experiments the following media were developed to assist in the separation of Streptococcus faecalis and $S$. faecium.

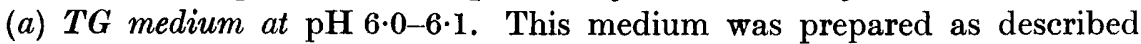
above, but was adjusted to an initial $\mathrm{pH}$ of $6 \cdot 0-6 \cdot 1$. Instead of extracting the formazan after overnight incubation with the test organisms, the cultures were shaken with $5 \mathrm{ml}$. of $n$-butanol and allowed to settle. Positive reactions were indicated by a bright red butanol layer whilst negative reactions were either colourless or very pale pink. About 70 of the isolates of Streptococcus faecalis and $S$. faecium, which had previously been tested in TG medium at pH 6.8-7.0 with the results shown in Fig. 2, were re-tested in the TG medium at $\mathrm{pH} 6.0$ by this qualitative method. The strains could now be divided easily into $S$. faecalis with the bright red reaction and $S$. faecium with a colourless 
reaction. The only exceptions were those few strains which had previously been atypical-in the case of $S$. faecalis having a low reducing power, and with $S$. faecium having an exceptionally high one.

(b) Tetrazolium agar for isolating Streptococcus faecalis and S. faecium. A useful extension of the methods described above was the preparation of a solid medium for separating these two organisms. This medium had the same composition as TG medium but the concentration of tetrazolium was increased to $0.01 \%$, and it was solidified by addition of $1.2 \%(\mathrm{w} / \mathrm{v})$ New Zealand agar; the $\mathrm{pH}$ value was adjusted to $6 \cdot 0-6 \cdot 1$. The agar, peptone, Lemco and salt was autoclaved at $15 \mathrm{lb}$./sq.in. for $20 \mathrm{~min}$. in $95 \mathrm{ml}$. lots and the glucose and tetrazolium solutions added immediately before the plates were poured. The plates were streaked with cultures of the test organisms and incubated for 1 or 2 days at $37^{\circ}$. Isolated colonies of Streptococcus faecalis were deep red, whilst those of $S$. faecium were colourless. When cultures of $S$. faecalis were mixed with $S$. faecium it was quite easy to separate the two species again by this method.

\section{DISCUSSION}

The results given in this paper emphasize the great differences in the reducing powers of the two related species, Streptococcus faecium and $S$. faecalis, and substantiate the position of $S$. faecium (Orla-Jensen) as a species distinct from $S$. faecalis and its variants zymogenes and liquefaciens. Within the Lancefield group $\mathbf{D}, S$. faecium appears to occupy an intermediate position between $S$. faecalis on the one side and $S$. durans and $S$. bovis on the other.

As there was a difference in $E_{h}$ of over $100 \mathrm{mV}$. between the cultures of Streptococcus faecalis and $S$. faecium grown under the same conditions, it was possible to adjust the initial $\mathrm{pH}$ value of TG medium so that with $S$. faecium there was no reduction of tetrazolium during growth, whilst with $S$. faecalis the tetrazolium was almost entirely reduced.

This test with TG medium at $\mathrm{pH} 6.0$ augments the other distinguishing tests given in Table 1 . The advantage of using tetrazolium in such a test is that the production of the insoluble formazan is an irreversible reaction. This is important as it was observed in all the redox potential experiments with TG medium that the $E_{h}$ rose rapidly before growth had ceased. Hewitt (1950) also found this with other streptococci, the rise in potential being attributed to the production of hydrogen peroxide. Hence, with a reversible redox indicator such as methylene blue, reduction is liable to be only temporary, making the test ambiguous.

In the experiments described above it is evident that the reduction of tetrazolium took place in cultures of a much higher redox potential than would be expected from the $\boldsymbol{E}_{0}$ of $-\mathbf{8 0} \mathrm{mV}$. at $\mathrm{pH} 6 \cdot 72$ given by Jerchel \& Mohle (1944). From the information available it seems that once the potential falls below about $E_{h}+150 \mathrm{mV}$. reduction of tetrazolium begins.

The tetrazolium glucose agar medium at $\mathrm{pH} \mathrm{6.0} \mathrm{has} \mathrm{been} \mathrm{found} \mathrm{most}$ valuable for distinguishing the colonies of Streptococcus faecalis from $S$. faecium and the other Lancefield group D streptococci. 
Cooper \& Ramadan (1955) showed that true Streptococcus faecalis organisms which strongly reduced litmus milk and also Janus Green were typical of human faeces. They isolated a number of strains from bovine and sheep faeces which they listed as atypical $S$. faecalis strains and which were shown to have low reducing powers. These organisms were probably similar to the $S$. faecium strains described in this paper. Unfortunately the concentration of potassium tellurite (1/5000) used by Cooper \& Ramadan was too low to inhibit their atypical strains if indeed they were $S$. faecium. Skadhauge (1950) showed that $1 / 2500$ tellurite was the optimal concentration for separating $S$. faecalis and $S$. faecium; at higher dilutions $S$. faecium would grow.

The work described in this paper was carried out as part of the programme of the Food Investigation Organization of the Department of Scientific and Industrial Research. The experimental work was carried out with the technical assistance of Mr G. Ingram and Mr K. H. Robinson.

\section{REFERENCES}

Barnes, E. M. \& Ingram, M. (1955). 'The identity and origin of faecal streptococci in canned hams. Ann. Inst. Pasteur, Lille, 7, 115.

Cooper, K. E. \& Ramadan, F. M. (1955). Studies in the differentiation between human and animal pollution by means of faecal streptococci. J. gen. Microbiol. $12,180$.

Dack, G. M. (1944). Food Poisoning. Chicago: The University of Chicago Press.

Fairbridge, R. A., Willis, K. J. \& Bоoth, R. G. (1951). The direct colorimetric estimation of reducing sugars and other reducing substances with tetrazolium salts. Biochem. J. 49, 423.

Hewitt, L. F. (1950). Oxidation-Reduction Potentials in Bacteriology and Biochemistry, 6th edn. Edinburgh: E. and S. Livingstone Ltd.

Ingram, M. \& Barnes, E. M. (1955). Streptococci in pasteurised canned hams. Ann. Inst. Pasteur, Lille, 7, 101.

Jи́мвов, B. (1954). Reduction of tetrazolium salt. Nature, Lond. 173, 774.

Jerchel, D. \& Mohle, W. (1944). Die Bestimmung des Reduktions potentials von Tetrazolium verbindungen. Ber. dtsch. chem. Ges. 77 B, 591.

Laxminarayana, H. \& IYA, K. K. (1953). Studies on the reduction of tetrazolium by lactic acid bacteria. I. Dye reducing activities of different species. Indian J. Dairy Sci. 6, 75.

Orla-Jensen, S. (1919). The Lactic Acid Bacteria. Copenhagen: A. F. Høst.

Seelemann, M. \& Carstens, O. (1951). Die serologische Zugehörigkeit des Sc. bovis und sog. atypischer Enterokokken zur Gruppe D. Kieler Milchw. Forsch. Ber. $3,431$.

Sharpe, M. E. \& Shattock, P. M. F. (1952). The serological typing of group D streptococci associated with outbreaks of neonatal diarrhoea. J. gen. Microbiol. 6, 150.

Sнatтоск, P. M. F. (1955). The identification and classification of Streptococcus faecalis and some associated streptococci. Ann. Inst. Pasteur, Lille, 7, 95.

Sherman, J. M. (1937). The streptococci. Bact. Rev., $1,1$.

SkADHAUGE, K. (1950). Studies on Enterococci with Special Reference to the Serological Properties. Copenhagen: Einar Munksgaards. 